\title{
Determinación de la calidad microbiológica de mejillón (Mytella guyanensis: Mytilidae) en Puerto Palito, Isla de Chira en el Pacífico Costarricense
}

\author{
Fiorella González ${ }^{1}$, Marlon Salazar ${ }^{2}$, Rodrigo Méndez ${ }^{3}$, Karol Saravia ${ }^{4}$
}

1. Universidad Estatal a Distancia, Costa Rica. Programa Ingeniería Agroindustrial.correo: figonzalez@uned.ac.cr, Sabanilla, Costa Rica.

2. Universidad Estatal a Distancia, Costa Rica. Manejo de Recursos Naturales. correo: masalazar@uned.ac.cr, Sabanilla, Costa Rica.

3. Universidad Estatal a Distancia, Costa Rica. Programa de Laboratorios. correo: rmendezs@uned.ac.cr, Sabanilla, Costa Rica.

4. Universidad Estatal a Distancia, Costa Rica. Programa Ingeniería agroindustrial. correo: ksaravia@uned.ac.cr, Sabanilla, Costa Rica.

Recibido: 25 de febrero de 2020

\section{RESUMEN}

Esta investigación tuvo como objetivo determinar la cantidad de coliformes fecales en carne y agua de mejillón, además de identificar si las condiciones de temperatura, $\mathrm{pH}$, salinidad fueron favorables, asimismo si el tipo de manipulación que se le da contribuye al crecimiento microbiano. El alcance fue obtener valores reales de contaminación y presencia o ausencia de microorganismos característicos que se encuentra en estos moluscos, análisis que se realizaron en época lluviosa debido a que existe un mayor arrastre de afluentes que trasladan contaminantes. La metodología consistió en realizar análisis microbiológicos a muestras de carne y concha en etapa de siembra del mejillón y se analizó según métodos estandarizados de laboratorio. Dentro de los resultados de análisis microbiológicos y comparados con el Reglamento Técnico Centroamericano, en el caso de la carne se encontraba dentro de los límites de los criterios microbiológicos establecidos y en el caso del agua la cantidad de coliformes fecales fue menor a 1(N.M.P/100 ml). Se concluyó que la muestra analizada es un potencial riesgo para la salud del consumidor, al poseer $9.5 \times 10{ }^{1} \mathrm{UFC} / \mathrm{g}$ de E. coli, sumado a que si no hay una correcta manipulación (no hay lavado de manos, no se depura el producto) además de las condiciones del medio (temperatura, humedad) se favorece la multiplicación de microorganismos coliformes fecales en el alimento en la zona de estudio. Otras causas identificadas del aumento de riesgo de patógenos son la extracción del mejillón de su medio, el abuso de tiempo y temperatura y la manipulación inadecuada. El procedimiento recomendado para bajar la carga microbiana según las condiciones del mejillón cultivado en la zona en estudio
Aceptado: 05 de Mayo de 2020

es la depuración previa a su cocción y consumo.

Palabras claves: análisis microbiológico, calidad microbiológica, comunidad, cultivo, inocuo, bivalvo.

\begin{abstract}
Determination of the microbiological quality of mussels (Mytella guyanensis: Mytilidae) in Puerto Palito, Chira Island in the Costa Rican Pacific region.
\end{abstract}

This research aimed to determine the amount of fecal coliforms in meat and water of mussel, in addition to identifying if temperature, $\mathrm{pH}$, and salinity conditions were favorable, as well as if the type of manipulation that is given contributes to microbial growth. The scope was to obtain real values of contamination and presence or absence of microorganisms found in these molluscs; the analyzes were carried out in the rainy season due to the fact that there is a greater drag of tributaries that carry contaminants. The methodology consisted of carrying out microbiological analyzes on meat and shell samples at the mussel planting stage, analyzed according to standard laboratory methods. Within the results of microbiological analysis, and compared with the Central American Technical Regulation (RTC, nd), the meat was within the limits of the established microbiological criteria and in the case of water the amount of fecal coliforms was lower. at 1 (MPN / $100 \mathrm{ml})$. It was concluded that the analyzed sample is a potential risk for the consumer's health, since it has $9.5 \times 101 \mathrm{CFU} / \mathrm{g}$ of $E$. coli; added to the fact that if there is no correct handling (there is no hand washing, the product) in addition to the environmental conditions (temperature, 
humidity), the multiplication of fecal coliform microorganisms in the food in the study area is favored. Other identified causes of the increased risk of pathogens are the extraction of the mussel from their environment, the abuse of time and temperature with improper handling. The recommended procedure to lower the microbial load according to the conditions of the mussel grown in the study area is to conduct purification prior to cooking and consumption.

Key words: microbiological analysis, microbiological quality, farming community, innocuous, bivalve.

\section{Introducción}

Con el fin de mejorar las condiciones sociales, ambientales y económicas de la población pesquera y su asociación en Puerto Palito en Isla de Chira en el golfo de Nicoya, Costa Rica, se generó un proyecto de investigación, extensión y docencia en el cual se propuso y desarrolló el cultivo de forma controlada del bivalvo Mytella guyanensis (Mytilidae) autóctono de la zona en la que se involucraron 14 familias de la comunidad. Dentro de los objetivos del proyecto, se planteó brindar una alternativa económica a la población de Puerto Palito, además que el producto final sea inocuo para ser comercializado, Corrales ,2015 menciona que existe una creciente preocupación por el impacto en la salud humana que pueda tener el consumo de moluscos. Estos animales, debido a su forma de alimentación, pueden contener grandes cantidades de contaminantes, incluyendo metales pesados como el cadmio (Cd), mercurio $(\mathrm{Hg})$ y plomo $(\mathrm{Pb})$, tres de los contaminantes metálicos más comunes producidos por las industrias (Corrales, 2015). Debido a su naturaleza tóxica estos contaminantes deben ser monitoreados en los alimentos de consumo humano, su uso y eliminación está ahora regulada por los países industrializados.

En el caso de Costa Rica el consumo de moluscos que son objeto de extracción con fines comerciales en la costa Pacífica son principalmente las conchas negras, almejas, ostras y mejillones. Las comunidades locales tienen como costumbre durante el pasar del tiempo como actividad económica de la zona la extracción de moluscos de forma artesanal, en algunos casos la actividad es meramente un medio de subsistencia y auto consumo (Oficina comercial de prochile, 2017).

Como reseña se indica que los pobladores de isla de Chira extraían el mejillón de cualquier tamaño agotando los bancos naturales de crecimiento, bivalvos que se encuentran enterrados en el barro cerca de los manglares, afectando su hábitat y su disponibilidad, debido a lo anterior se desarrolló una forma de cultivo controlado iniciando en el 2017 a la fecha; se utiliza un método en el cual se usan canastas (contienen semillas de mejillón) en balsas flotantes o sistemas Long Line y así se ha pensado en repoblar el banco natural como forma de conservación del medio de crecimiento natural y evitar su extinción; en estas condiciones de cultivo se generó un control de crecimiento.
El alcance del proyecto fue obtener valores reales de contaminación y presencia o ausencia de microorganismos característicos que se encuentra en estos moluscos. La importancia de tratar este tema en este artículo se debe al riesgo potencial de salud pública por intoxicación tanto microbiana como por metales pesados que poseen los mejillones al ser filtradores y convertirse en un alimento de baja inocuidad Por otro lado, se debe recalcar que los estudios de este tema son de los años 70 y 80 debido que no existe cultivo de mitílidos sino extracción de bancos naturales en el trópico y no hay cultura de consumo nacionalizado de este tipo de bivalvos, por lo que las referencias bibliográficas son escasas y desactualizadas.

Los mejillones son bivalvos ricos en nutrientes como proteínas, pero debe recordarse que al ser organismos filtradores tienen la capacidad de concentración de varios elementos a un nivel muy superior de su entorno inmediato externo; estos compuestos o sustancias podrían convertirse en peligrosos focos de infección por microorganismos patógenos (virus y bacterias). Por lo tanto, es necesario realizar un proceso de limpieza de los organismos para tratar de eliminar o disminuir a niveles aceptables tales patógenos, y al estar sumergidos en lodos durante una parte de su ciclo de vida tienen una alta probabilidad de que en este medio exista una elevada contaminación por diversas fuentes pudiendo contener desde materia orgánica, fecal, barro entre otros contaminantes (Cáceres, \& Vásquez, 2014).

A efectos de controlar los peligros, es muy importante la identificación y vigilancia de las zonas de cría para la inocuidad de los moluscos bivalvos. La inocuidad de los alimentos es un atributo fundamental de la calidad y puede definirse como el conjunto de condiciones y medidas necesarias durante la producción, almacenamiento, distribución y preparación de los alimentos para asegurar que, una vez ingeridos no representen un riesgo apreciable para la salud. No se puede prescindir de la inocuidad de un alimento se genera en la producción primaria es decir en la finca y se transfiere a otras fases de la cadena alimentaria como el procesamiento, el empaque, el transporte, la comercialización, la preparación del producto y su consumo. (Ministerio de Salud y protección social 2013).

Según indica la organización de las naciones unidad para la alimentación y la agricultura, 2020 garantizar la inocuidad de los alimentos es una prioridad de salud pública y un paso esencial para lograr la seguridad alimentaria. La eficacia de los sistemas de control de la calidad e inocuidad de los alimentos es vital no solo para salvaguardar la salud y el bienestar de las personas, sino también para impulsar el desarrollo económico y mejorar los medios de vida al promover el acceso a los mercados nacionales, regionales e internacionales.

Por lo que la calidad microbiana debe de cuidarse en el bivalvo que va a ser consumido y asegurarla para su venta, con la finalidad de no causar una enfermedad de origen alimentario. 
Desde el punto de vista de la sanidad e inocuidad alimentaria, el cultivo de moluscos bivalvos debe llevarse a cabo en aguas limpias libres de contaminantes. Otro aspecto fundamental derivado de la forma de alimentación de los moluscos bivalvos, es la acumulación de biotoxinas producidas por microalgas, algunas sólo afectan al molusco, pero otras pueden ser nocivas para el ser humano. (Organización del sector pesquero y acuícola del itsmo centroamericano, 2014). Se requiere realizar actividades previas y posterior a su producción, con el objetivo de obtener productos con calidad sanitaria e inocuas, según normas o leyes en materia de productos del mar. La inocuidad de los moluscos se ve afectada por contaminación provocada por industrias, ríos, humanas, fenómenos naturales y un aspecto importante la carente o casi inexistente higiene del personal que los manipula.

En la producción de moluscos bivalvos, el principal peligro conocido es la contaminación biológica de las aguas en donde se cultivan, principalmente cuando éstos son destinados a consumirse en crudo. Puesto que los moluscos son filtradores, en ellos los contaminantes se concentran en niveles mucho más altos que los de las aguas marinas circundantes. Por consiguiente, la contaminación por bacterias y virus, en la zona de cultivo, es de crucial importancia en la especificación del producto a consumirse y su presencia está relacionada con la contaminación del agua por heces fecales humanas (coliformes), provocando gastroenteritis, hepatitis infecciosa o fiebre tifoidea. Sin embargo, también puede haber contaminación en la zona de cultivo por aguas negras o agrícolas a través de los escurrimientos en los períodos de lluvia (Organización del sector pesquero y acuícola del itsmo centroamericano, 2014).

El control sanitario de riesgos microbiológicos es tan importante, y constituye una medida sanitaria básica para mantener un grado de salud adecuado en la población. La identificación, clasificación y vigilancia de cadena de producción de mejillón es tarea de las autoridades competentes en cooperación con los pescadores y productores primarios. Pueden utilizarse el recuento de E. coli/coliformes fecales o el recuento total de coliformes como indicadores de la posible contaminación fecal. Si se encuentran biotoxinas en la carne de moluscos bivalvos en cantidades peligrosas, debe cerrarse la zona de cría a la recolección de moluscos bivalvos hasta que la investigación toxicológica aclare que la carne de tales moluscos está exenta de cantidades peligrosas de biotoxinas. (Cáceres y Vasquez,2014).

Las bacterias coliformes son indicadores de contaminación fecal El grupo de microorganismos coliformes es adecuado como indicador de contaminación fecal debido a que estos forman parte de la microbiota normal del tracto gastrointestinal, tanto del ser humano como de los animales homeotermos y están presentes en grandes cantidades en él. Los microorganismos pertenecen a la familia Enterobacteriaceae (Larrea et al.,2012). Dentro de la familia Enterobacteriaceae está la E. coli, sobreviven durante meses en el estiércol contaminando las aguas superficiales (bebida y riego), las verduras y frutas y la superficie de las tierras de cultivo (Fundación Vasca para la seguridad y agroalimentaria, 2013)

Los moluscos también juegan un papel fundamental en la transmisión de enfermedades ya que su capacidad de filtración y acumulación de materia orgánica favorece la presencia de bacterias en su interior. En la producción de moluscos bivalvos, el principal peligro conocido es la contaminación biológica de las aguas en donde se cultivan, principalmente cuando éstos son destinados a consumirse en crudo se convierten en un problema de salud. También puede haber contaminación en la zona de cultivo por aguas negras o agrícolas a través de los escurrimientos en los períodos de lluvia. (Organización del sector pesquero y acuícola del itsmo centroamericano, 2014)

Para seguir consumiendo este tipo de bivalvos y bajar la posibilidad de riesgo de enfermedad de origen alimentario, es necesario en este tipo de moluscos someter el producto a un sistema de depuración, el cual consiste en una técnica aplicada para eliminar contaminantes microbianos (patógenos y toxinas) en los moluscos bivalvos, Estos son inmersos en tanques en agua de mar limpia esterilizada para que lleven a cabo su actividad normal de filtración y expulsar los contaminantes de sus branquias y aparato digestivo durante un período de tiempo determinado (Cáceres y Vásquez, 2014).

El fin de plasmar los hallazgos en este documento se debió a la necesidad de conocer las condiciones sobre las cuales se cultiva el mejillón en un sistema controlado pero expuesto al medio ambiente marino, para lo cual se realizó un estudio microbiológico previo para determinar la calidad del bivalvo en una etapa de siembra (menor a tres meses) ya que en este periodo se encuentra en la época de desdoble. Esta operación tiene como propósito aumentar el espacio y disminuir la densidad por $\mathrm{cm} 2$ para su desarrollo, además permite que crezcan rápida y uniformemente (Sello de calidad, 2014).

Los objetivos específicos del estudio son, determinar la cantidad de coliformes fecales en una muestra representativa de mejillón y obtener las condiciones de temperatura, $\mathrm{pH}$, salinidad en la zona en estudio, determinar si el tipo de manipulación que se le da comúnmente al mejillón perjudica la inocuidad del alimento. Además, se abordar obtener información sobre la composición nutricional del bivalvo; relacionando esto con su utilización para el crecimiento de algunos microorganismos que pueden proliferar y afectar su inocuidad, sin dejar de lado la comparación con el reglamento técnico centroamericano y sus criterios microbiológicos de vigilancia. El control sanitario de riesgos microbiológicos es tan importante, y constituye una medida sanitaria básica para mantener un grado de salud adecuado en la población. La identificación, clasificación y vigilancia de cadena de producción de mejillón es tarea de las autoridades competentes en cooperación con los pescadores y productores primarios. 
Pueden utilizarse el recuento de E. coli/coliformes fecales o el recuento total de coliformes como indicadores de la posible contaminación fecal. Si se encuentran biotoxinas en la carne de moluscos bivalvos en cantidades peligrosas, debe cerrarse la zona de cría a la recolección de moluscos bivalvos hasta que la investigación toxicológica aclare que la carne de tales moluscos está exenta de cantidades peligrosas de biotoxinas. (Cáceres y Vasquez,2014).

Las bacterias coliformes son indicadores de contaminación fecal El grupo de microorganismos coliformes es adecuado como indicador de contaminación fecal debido a que estos forman parte de la microbiota normal del tracto gastrointestinal, tanto del ser humano como de los animales homeotermos y están presentes en grandes cantidades en él. Los microorganismos pertenecen a la familia Enterobacteriaceae (Larrea et al.,2012). Dentro de la familia Enterobacteriaceae está la E. coli, sobreviven durante meses en el estiércol contaminando las aguas superficiales (bebida y riego), las verduras y frutas y la superficie de las tierras de cultivo (Fundación Vasca para la seguridad y agroalimentaria, 2013)

Los moluscos también juegan un papel fundamental en la transmisión de enfermedades ya que su capacidad de filtración y acumulación de materia orgánica favorece la presencia de bacterias en su interior. En la producción de moluscos bivalvos, el principal peligro conocido es la contaminación biológica de las aguas en donde se cultivan, principalmente cuando éstos son destinados a consumirse en crudo se convierten en un problema de salud. También puede haber contaminación en la zona de cultivo por aguas negras o agrícolas a través de los escurrimientos en los períodos de lluvia. (Organización del sector pesquero y acuícola del itsmo centroamericano, 2014)

Para seguir consumiendo este tipo de bivalvos y bajar la posibilidad de riesgo de enfermedad de origen alimentario, es necesario en este tipo de moluscos someter el producto a un sistema de depuración, el cual consiste en una técnica aplicada para eliminar contaminantes microbianos (patógenos y toxinas) en los moluscos bivalvos, Estos son inmersos en tanques en agua de mar limpia esterilizada para que lleven a cabo su actividad normal de filtración y expulsar los contaminantes de sus branquias y aparato digestivo durante un período de tiempo determinado (Cáceres y Vásquez, 2014).

El fin de plasmar los hallazgos en este documento se debió a la necesidad de conocer las condiciones sobre las cuales se cultiva el mejillón en un sistema controlado pero expuesto al medio ambiente marino, para lo cual se realizó un estudio microbiológico previo para determinar la calidad del bivalvo en una etapa de siembra (menor a tres meses) ya que en este periodo se encuentra en la época de desdoble. Esta operación tiene como propósito aumentar el espacio y disminuir la densidad por $\mathrm{cm} 2$ para su desarrollo, además permite que crezcan rápida y uniformemente (Sello de calidad, 2014).
Los objetivos específicos del estudio son, determinar la cantidad de coliformes fecales en una muestra representativa de mejillón y obtener las condiciones de temperatura, $\mathrm{pH}$, salinidad en la zona en estudio, determinar si el tipo de manipulación que se le da comúnmente al mejillón perjudica la inocuidad del alimento. Además, se abordar obtener información sobre la composición nutricional del bivalvo; relacionando esto con su utilización para el crecimiento de algunos microorganismos que pueden proliferar y afectar su inocuidad, sin dejar de lado la comparación con el reglamento técnico centroamericano y sus criterios microbiológicos de vigilancia.

\section{Metodología}

Para determinar la calidad microbiológica de mejillón son necesarios análisis microbiológicos en etapa de siembra del mejillón, por lo que la metodología se basó en tomar muestras de carne y concha y de agua del medio de cultivo (se realizó la toma de muestras en época seca, mes de febrero y así conocer la carga microbiana de los mismos. Se trasladaron las muestras al laboratorio LAMBDA ente certificado para este tipo de análisis en un contenedor a temperaturas ente 8 y $10^{\circ} \mathrm{C}$.

Se siguió el siguiente procedimiento:

Se tomaron dos tipos de muestra en la zona de estudio

A. Carne y concha de mejillón:

1. Se sacaron aleatoriamente 10 canastas colocadas en balsas flotantes, ubicadas en puerto palito donde se cultiva el mejillón (Mytella guyanensis: Mytilidae) tenían de 5 a 6 meses de crecimiento (con individuos de entre 3,5 a 6,6 cm de largo); estas estaban sumergidas en el mar a una profundidad de 3 metros.

2. Se abrieron las canastas, se seleccionaron individuos sanos (cerradas) se limpiaron y se tomaron los 800 gramos de carne y concha; se empacaron en bolsa de etileno de alta densidad y se anudó. Se colocaron en una hielera con termómetro para controlar temperatura y que estuviera en un promedio de 10 a $12{ }^{\circ} \mathrm{C}$ durante las cuatro horas hasta llegar al destino de análisis.

3. A la muestra total de 800 gramos se les aplicó el método analítico bacteriológico establecido en el bacteriological analytical manual (B.A.M) de la FDA (Food and Drug administation) método del año 2001 (esto indicado por el laboratorio). 
B. Muestra de agua:

La muestra de agua de mar (1 litro) se tomó en varios puntos del cultivo de mejillón y se colocó en un envase ámbar de vidrio para ser transportado en hielera, manteniendo una temperatura no superior a los $12^{\circ} \mathrm{C}$ durante las cuatro horas hasta llegar al destino de análisis. El método analítico utilizado para la muestra fue el Standard Methods for the examinación of Wáter and Wastewater $22^{\text {st }}$ Edition, 2012: 9020 B (3), 9020B (8), 9020 B (9), 9223A, 9223B. se utilizaron métodos Pt-14 para la determinación de coliformes totales, termo tolerantes y E coli. (esta metodología es establecida por el laboratorio certificado).

\section{Resultados y Discusión}

Para el análisis de los resultados se tomó como comparación lo estipulado en el RTCA 67.04.50:17 el cual tiene como objeto establecer los parámetros microbiológicos de la inocuidad de los alimentos y sus límites de aceptación para el registro y la vigilancia en los puntos de comercialización (Ministerio de salud, 2005).

En el cuadro 1 se reflejan los resultados del análisis de carne de mejillón, evidenciado la presencia de coliformes totales, y de Escherichia coli y como ausente Salmonella s.p.

Cuadro 1. Análisis microbiológico de carne de mejillón.

\begin{tabular}{|l|l|}
\hline Microorganismo & Datos \\
\hline Salmonella s.p. & Ausente en $25 \mathrm{~g}$ \\
\hline Coliformes totales & $<10 \mathrm{UFC} / \mathrm{g}$ \\
\hline E.coli & $9.5 \times 10^{1} \mathrm{UFC} / \mathrm{g}$ \\
\hline
\end{tabular}

Fuente Elaboración propia, 2018

\begin{tabular}{|c|c|c|c|c|c|c|}
\hline $\begin{array}{l}\text { 9.0 Grupo de Alimento: Pescado, derivado } \\
\text { fresco y para diversos productos marinos elaborad } \\
\text { invertebrados acuáticos (p. ej., medusas), los molv } \\
\text { productos marinos se pueden recubrir, p. ej. con } \\
\text { congelados y glaseados). En el SCA esto se indica }\end{array}$ & $\begin{array}{l}\text { y produ } \\
\text { os. Se inclu } \\
\text { cos (p. ej., } \\
\text { glaseados o } \\
\text { on una ano }\end{array}$ & $\begin{array}{l}\text { arinos } \\
\text { ella los } \\
\text { y cara } \\
\text { s, antes } \\
\text { elativa }\end{array}$ & & & $\begin{array}{l}\text { divide en cat } \\
\text { feros acuátic } \\
\text { amarones can } \\
\text { consumo (p } \\
\text { miento (trata }\end{array}$ & $\begin{array}{l}\text { para el pescado } \\
\text { ej, ballenas), los } \\
\text { langostas). Los } \\
\text { letes de pescado } \\
\text { de superficie)" }\end{array}$ \\
\hline $\begin{array}{l}\text { 9.1 Subgrupo del alimento: Pescado y prod } \\
\text { equinodermos, desconchados, frescos, emp }\end{array}$ & $\begin{array}{l}\text { actos mar } \\
\text { cados }\end{array}$ & rescos, & & & uscos no bi & s, crustáceos y \\
\hline Parámetro & & lan de & & & & \\
\hline & $\begin{array}{c}\text { Tipo de } \\
\text { riesgo }\end{array}$ & clase & $\mathbf{n}$ & c & m & M \\
\hline Escherichia coli & & 3 & & 3 & $10 \mathrm{UFC} / \mathrm{g}$ & $10^{2} \mathrm{UFC} / \mathrm{g}$ \\
\hline \begin{tabular}{|l|} 
Staphylococcus aureus (Solo para pescados) \\
\end{tabular} & & 3 & & 1 & $10 \mathrm{UFC} / \mathrm{g}$ & $10^{3} \mathrm{UFC} / \mathrm{g}$ \\
\hline Salmonella ssp/25 g & A & 2 & 5 & 0 & Ausencia & -- \\
\hline $\begin{array}{l}\text { Listeria monocytogenes } / 25 \mathrm{~g} \text { (solo para } \\
\text { producto crudo listo para consumo, ejemplo } \\
\text { sushi y ceviche) }\end{array}$ & & 2 & & 0 & Ausencia & -- \\
\hline Vibrio cholerae $\mathrm{Ol}$ & & 2 & & 0 & Ausencia & $+\overline{-1}$ \\
\hline \begin{tabular}{|l} 
Vibrio parahaemolyticus (solo para bivalvos) \\
\end{tabular} & & 3 & & 2 & $10 \mathrm{UFC} / \mathrm{g}$ & $10^{3} \mathrm{UFC} / \mathrm{g}$ \\
\hline
\end{tabular}

Figura 1. Criterios microbiológicos para vigilancia

Fuente: Ministerio de salud (2005) criterios microbiológicos para la inocuidad de alimentos. San José Costa Rica

Como se observa en el cuadro 1 se indican coliformes totales y E. coli separados, lo anterior ya que no todos los coliformes son de origen fecal, por lo que se hizo necesario desarrollar pruebas para diferenciarlos a efectos de emplearlos como indicadores de contaminación. Se distinguen, por lo tanto, los coliformes totales que comprende la totalidad del grupo y los coliformes fecales (E coli) aquellos de origen intestinal (calidad microbiológica, 2019).
Comparando el cuadro 1 y la figura 1 se muestra que en el caso de la $E$ coli, estos indican valores menores a 10 UFC/g; según Ministerio de salud, 2005 en el reglamento técnico centroamericano se indican los criterios microbiológicos para vigilancia de bivalvos donde se reporta que el límite aceptable no puede superar 10 $\mathrm{UFC} / \mathrm{g}$, el análisis realizado en zona de cultivo demuestra que está en el límite del rango, relacionada con los criterios microbiológicos (aceptabilidad de un producto o un lote de un alimento basada en la ausencia o presencia, o en la cantidad de microorganismos, 
incluidos parásitos, y/o en la cantidad de sus toxinas/metabolitos, por unidad o unidades de masa, volumen, superficie o lote); aunque lo anterior es un indicador que no hay coliformes fecales el estar al límite del rango esto acrecienta el hecho que una incorrecta manipulación o la no aplicación de un método de depuración idóneo, podría acrecentar el riesgo de sobrepasar esos límites.

El manejo inadecuado durante su manipulación en limpieza, cosecha, traslado, empaque, cocción entre otras etapas luego de cosecha puede generar una contaminación cruzada la cual es la presencia de entidades físicas, químicas o biológicas indeseables procedentes de otros procesos de producción que pueden alterar el producto; El mejor método para producir moluscos de una manera segura es el cultivo y la recolección en áreas que no estén sometidas a ninguna fuente externa de contaminación (Organización del sector pesquero y acuícola del itsmo centroamericano, 2014)

En el caso de coliformes totales su valor es $<10 \mathrm{UFC} / \mathrm{g}$ dentro del grupo de los coliformes totales existe un subgrupo que es el de los Coliformes fecales. comprenden principalmente Escherichia coli y Escherichia, Klebsiella, Enterobacter, Citrobacter (calidad microbiológica, 2019).

Se debe tomar en cuenta que sí hay presencia de los mismos, esto deja la alerta que con las condiciones que se le aportan al microorganismo patógeno como proteínas, vitaminas, minerales, propias del mejillón (figura 2) y sumado a las condiciones ambientales de temperatura, humedad relativa, mala manipulación, abuso de tiempo y temperatura; puede multiplicarse aceleradamente durante la cosecha y convertirse en un producto con riesgo potencial para la salud del consumidor lo anterior ya que como indica Montes (2013) para multiplicarse los microorganismos requieren nutrientes, de los que son ricos los alimentos y por ello es fácil el crecimiento microbiano. Según Organización del sector pesquero y acuícola del itsmo centroamericano, 2014 los moluscos en general poseen una alimentación por filtración. Este sistema de nutrición permite la acumulación de materia orgánica y favorece la presencia de bacterias en su interior. y otros elementos presentes en el ambiente donde los bivalvos se desarrollan.

Por otro lado, indica Montes, 2013 sugiere que los moluscos bivalvos tienen la capacidad de acumular materiales del ambiente, por lo que constituye un riesgo potencial para la salud el consumidor, varios tipos de microorganismos tiene la capacidad de ser acumulados por estos organismos.Según manipulador de alimentos, 2020 las principales vías de contaminación del alimento son agua (contaminada o no potable), polvo, tierra, aire, superficies, manos sucias, u otros alimentos a través de todos ellos se transmiten microorganismos que pueden contaminar el alimento.

\begin{tabular}{|r|l|}
\hline Nutrientes & Cantidad (100 gramos) \\
\hline Energía & $68 \mathrm{kcal} / \mathrm{g}$ \\
\hline Proteína & $10.8 \mathrm{~g}$ \\
\hline Grasa total $(\mathrm{g})$ & 2 \\
\hline Colesterol $(\mathrm{mg})$ & 100 \\
\hline Glúcidos $(\mathrm{g})$ & 1.90 \\
\hline Calcio $(\mathrm{mg})$ & 200 \\
\hline Hierro $(\mathrm{mg})$ & 7.70 \\
\hline Yodo $(\mathrm{ug})$ & 120 \\
\hline Vitamina E (mg) & 0.90 \\
\hline Vitam. B 12(ug) & 22.10 \\
\hline Folato (ug) & 27 \\
\hline
\end{tabular}

Figura 2. Composición nutricional del mejillón en 100 gramos.

Fuente: Fundación Universitaria Iberoamericana (2017)

En el análisis realizado al agua de mar (cuadro 3) arrojó que la cantidad de coliformes totales como fecales es $<1$ (N.M.P/100 ml) y comparando con el cuadro 2 por condiciones de salinidad, $\mathrm{pH}$, temperatura no son las ideales para desarrollo y supervivencia en agua, pero es indicador de acumulación en la carne. Lo anteriormente discutido es respaldado por Mora y Calvo, 2010 la Escherichia (coliformes fecal) no sobrevive un periodo largo en agua de mar, por lo que se convierte en un indicador de la contaminación bacteriológica en carne. Sosa, 2006 sugiere la utilización de ciertos organismos del grupo coliformes como indicadores de contaminación de origen fecal del agua.

CUADRO 2. Promedio de $\mathrm{pH}$ y salinidad del mar en zona de estudio año 2018

\begin{tabular}{llll}
\hline $\begin{array}{l}\text { Temperatura } \\
{ }^{\circ} \mathbf{C}\end{array}$ & $\mathbf{p H}$ & $\begin{array}{l}\text { Oxígeno } \\
\text { disuelto } \\
(\mathbf{m g} / \mathbf{L})\end{array}$ & $\begin{array}{l}\text { Salinidad } \\
(\mathbf{g} / \mathbf{L})\end{array}$ \\
\hline $\mathbf{2 8 - 3 1}$ & $8-13$ & $3-5.7$ & $19-28$ \\
\hline
\end{tabular}

Fuente: Elaboración propia, 2018.

El empleo de coliformes como indicadores de organismos patógenos en el agua es una práctica vigente en la actualidad. Los organismos coliformes son buenos indicadores de la calidad higiénica de los alimentos, se basa en la experiencia positiva adquirida en el agua. 
CUADRO 3 Análisis agua de mar.

\begin{tabular}{lll}
\hline Muestra & $\begin{array}{l}\text { Coliformes totales } \\
(\text { N.M.P/100ml) }\end{array}$ & $\begin{array}{l}\text { Coliformes fecales } \\
\text { (N.M.P/100ml) }\end{array}$ \\
\hline Agua de mar & $<1$ & $<1$ \\
\hline
\end{tabular}

Fuente: Elaboración propia, 2018.

Por otro lado, debe tenerse presente que $E$. coli, es un microorganismo que se utiliza a nivel mundial como un indicador de contaminación fecal (Organización mundial de la salud, 2018) observando los análisis se constata la presencia de estos microorganismos, aunque en valores menores que los que se indican en el RTCA, sin una correcta manipulación podría incrementar esos valores, que pueden ser causantes de enfermedades de origen alimentario (ETAs) y además indican contaminación fecal en la zona de estudio;

El resultado positivo de contaminación fecal en los moluscos y no así en el agua se explica por el proceso de filtración de aguas de los efluentes que llegan a las orillas del mar, así como heces de los animales como cerdo, gallina, perros, gatos entre otros que se encuentran en tierra firme en las inmediaciones de la zona de influencia del proyecto.

Al tomarse estos puntos anteriores se considera que durante los procesos previos al consumo del mejillón con una manipulación inadecuada se convierte este en producto no inocuo para las personas con un alto riesgo de adquirir enfermedades transmitidas por alimentos.

Es importante tener presente que los mejillones por ser de naturaleza filtradora tienden a acumular toxinas, microrganismos, sustancias químicas entre otros, debe recordarse que mientras permanecieron los bivalvos en la zona de cultivo filtraron las aguas para obtener su alimento y poder realizar sus necesidades biológicas y desarrollo como ser vivo; pero con el efecto de que todo ese tiempo que absorban agua estarán reservando y guardando en su músculo tanto las sustancias químicas como los microorganismos.

Las enfermedades de transmisión alimentaria abarcan un amplio espectro de dolencias y constituyen un problema de salud pública creciente en todo el mundo. Se deben a la ingestión de alimentos contaminados por microorganismos o sustancias químicas. $\mathrm{La}$ contaminación de los alimentos puede producirse en cualquier etapa del proceso que va de la producción al consumo de alimentos ( «de la granja al tenedor") y puede deberse a la contaminación ambiental, ya sea del agua, la tierra o el aire. (Organización mundial de la salud, 2018)

Las personas que los cultivan y cosechan son responsables de que se dé una manipulación correcta donde se evite contaminar el producto debido al tiempo de limpieza y desdoble que se lleva a cabo en las mesas de trabajo, por lo que deben garantizar la inocuidad, para esto existen procedimientos de limpieza y desinfección y procedimientos como la depuración, que garanticen la segura comercialización del producto, es importante en el mejor de los casos se realicen muestreos para garantizar lo establecido en el RTCA. Debido a que en la actualidad los mejillones se mantienen en agua de sal en constante cambio por un mínimo de 12 horas

\section{Conclusiones y Recomendaciones}

Aunque la cantidad de coliformes fecales en la muestra analizada estaba en el límite según RTCA, si es un potencial riesgo para la salud del consumidor, si no hay una correcta manipulación; para que no sobrepase los límites como lo indica el RTCA.

Las condiciones del medio como temperatura, acidez del medio $(\mathrm{pH})$, y salinidad determinadas en la época de recolección de las muestras favorecieron a la multiplicación de los coliformes fecales en el alimento estudiado la zona en estudio, según lo indican los resultados de los análisis y condiciones del medio que imperaban en el momento de tomar las muestras

Si el mejillón se extrae del medio y existe abuso de tiempo y temperatura y una manipulación inadecuada aumenta el riesgo de crecimiento de patógenos. Aspectos visualizados en la forma de manipulación de los pescadores de la isla.

Es recomendable realizar como etapa previa a la comercialización y consumo la depuración como mecanismo o procedimiento para bajar la carga microbiana, lo anterior comprobado por la literatura.

Es muy probable como indica la literatura que el manejo inadecuado durante su manipulación en limpieza, cosecha, traslado, empaque, cocción entre otras etapas luego de cosecha se convierte en una fuente de recontaminación.

Se recomienda hacer un estudio de metales pesados debido a que existe bibliografía que indica incidencia.

También se recomienda realizar una curva de depuración a los mejillones para determinar el tiempo necesario para que sea inocuo para consumo y comercialización.

Es importante se realice una línea microbiológica anual en época seca y lluviosa de microorganismos que presenta la carne de molusco. 


\section{Referencias}

Cáceres, j., Vásquez, R (2014) Manual de buenas prácticas para el manejo de cultivo de moluscos bivalvos Recuperado de: https://issuu.com/grafitechstudios/docs/manual_de_bue nas_pr_cticas_de_molu

Calidad microbiológica (2019). Análisis Microbiológico Coliformes Fecales. Recuperado de: http://www.calidadmicrobiologica.com.co/microbiolo gia/coliformes-fecales

Corrales, M. (16 de diciembre de 2015). Acumulación de metales pesados en bivalvos y sus efectos tóxicos en la salud humana: Perspectivas para el estudio en Costa Rica. Recuperado de:

https://revistas.ucr.ac.cr/index.php/pensamientoactual/article/view/22603

Fundación Vasca para la seguridad y agroalimentaria( 2013, 28 de febrero).Echerichia coli. Recuperado de: http://www.elika.net/datos/pdfs_agrupados/Documento 84/3.Ecoli.pdf

Laboratorio químico LAMBDA (2018, 15 de febrero). Resultados de análisis microbiológicos San José Costa Rica.

Larrea., Rojas, M., Álvarez. B., Rojas, Hernández, N., Heydrich, M. (2012) Bacterias indicadoras de contaminación fecal en la evaluación de la calidad de las aguas: revisión de la literaturaRevista CENIC. Ciencias Biológicas, 44 (3), pp 24-34. Recuperado de: https://www.redalyc.org/pdf/1812/181229302004.pdf

Manipulador de alimentos (2020). Contaminación de d alimentos. Recuperado de: https://manipulador-dealimentos.com/carnet-curso-contaminacion-de-losalimentos/

Ministerio de Salud de Costa Rica (2005, 15 de noviembre). Reglamento Técnico centroamericano 67.04.50:17Alimentos. criterios microbiológicos para la inocuidad de los alimentos .Recuperado de: https://members.wto.org/crnattachments/2017/SPS/CRI/ 17_2611_00_s.pdf

Ministerio de Salud y protección social (2013, 12 de octubre). Salud pública calidad e inocuidad de alimentos. Recuperado de: https://www.minsalud.gov.co/salud/Documents/generaltemp-

jd/LA\%20INOCUIDAD\%20DE\%20ALIMENTOS\%20 Y\%20SU\%20IMPORTANCIA\%20EN\%20LA\%20CA DENA\%20AGROALIMENTARIA.pdf

Ministerio de Salud y protección social (Minsalud, 2013) Salud pública calidad e inocuidad de alimentos Recuperado de: https://www.minsalud.gov.co/salud/Documents/general- temp-

jd/LA $\% 20 I N O C U I D A D \% 20 D E \% 20 A L I M E N T O S \% 20$ Y\%20SU\%20IMPORTANCIA\%20EN\%20LA\%20CA DENA\%20AGROALIMENTARIA.pdf

Montes, M. (2013). Factores que favorecen el crecimiento de microorganismos. Recuperado de: https://gestionintegra.com/factores-que-favorecen-elcrecimiento-bacteriano/

Mora, J., Calvo, G., ( 2010) Estado actual de contaminación con coliformes fecales de los cuerpos de agua de la Península de Osa. Tecnología en Marcha, 23 (5), pp. 34-40 Recuperado de: file:///C:/Users/ksaravia/Downloads/DialnetEstadoActualDeContaminacionConColiformesFecalesD $\underline{\text { eL-4835746.pdf }}$

Oficina Comercial de ProChile (2012, 27 de marzo). Estudio de mercado de moluscos congelados para el mercado de Costa Rica. Recuperado de: http://www.siicex.gob.pe/siicex/documentosportal/alert as/documento/doc/284803271rad93039.pdf

Organización de las naciones unidad para la alimentación y la agricultura (2020, 18 de abril). Inocuidad y calidad de los alimentos. Recuperado de: http://www.fao.org/food-safety/background/es/

Organización de las naciones unidas para la agricultura y la alimentación (2010, 22 de abril). Depuración de bivalvos: aspectos fundamentales y prácticos. Recuperado de: http://www.fao.org/3/a-i0201s.pdf

Organización de las naciones unidas para la alimentación y agricultura (2016, 24 de Octubre). Análisis e información comercial en pesquerías. Recuperado de: http://www.fao.org/in-

action/globefish/marketreports/resourcedetail/es/c/522565/

Organización mundial de la salud (2018, 7 de febrero). E. coli. Recuperado de : https://www.who.int/es/newsroom/fact-sheets/detail/e-coli

Organización del sector pesquero y acuícola del istmo centroamericano (2014, 9 de junio). manual de buenas prácticas de manejo para el cultivo de moluscos bivalvos. Recuperado

de:http://www.isamx.org/sitio/pdfs/Manual\%20de_BPd e_M_Version\%20Digital_011014155613.pdf

Red de Vigilancia para la Conservación y Protección de las Aguas Marinas y Costeras de Colombia (2011, 12 de mayo). Diagnóstico y evaluación de la calidad ambiental marina en el Caribe y Pacífico colombiano red de vigilancia para la conservación y protección de las aguas marinas y costeras de Colombia. Recuperado de: http://www.invemar.org.co/documents/10182/14479/Inf 
orme REDCAM 2011.pdf

Sello de calidad .(2014).Protocolo particular para acuicultura de mejillones Recuperado de: https://sellocalidadtdf.com.ar/wpcontent/uploads/2014/08/Acuicultura-cultivo-demejillones.pdf

Sosa, D. (2006). Determinación de contaminación por bacterias coliformes fecales en bahía de Jiquilisco, Usulután, utilizando como biomonitor Anadara similis y A. tuberculosa (Tesis doctoral). Universidad de el Salvador Recuperado de: http://ri.ues.edu.sv/id/eprint/12449/1/19200603.pdf

Cáceres, j., Vásquez, R (2014) Manual de buenas prácticas para el manejo de cultivo de moluscos bivalvos Recuperado de: https://issuu.com/grafitechstudios/docs/manual_de_bue nas pr cticas de molu

Calidad microbiológica (2019). Análisis Microbiológico Coliformes Fecales. Recuperado de: http://www.calidadmicrobiologica.com.co/microbiolo gia/coliformes-fecales

Corrales, M. (16 de diciembre de 2015). Acumulación de metales pesados en bivalvos y sus efectos tóxicos en la salud humana: Perspectivas para el estudio en Costa Rica. Recuperado de: https://revistas.ucr.ac.cr/index.php/pensamientoactual/article/view/22603

Fundación Vasca para la seguridad y agroalimentaria( 2013, 28 de febrero).Echerichia coli. Recuperado de: http://www.elika.net/datos/pdfs_agrupados/Documento 84/3.Ecoli.pdf

Laboratorio químico LAMBDA (2018, 15 de febrero). Resultados de análisis microbiológicos San José Costa Rica.

Larrea., Rojas, M., Álvarez. B., Rojas, Hernández, N., Heydrich, M. (2012) Bacterias indicadoras de contaminación fecal en la evaluación de la calidad de las aguas: revisión de la literaturaRevista CENIC. Ciencias Biológicas, 44 (3), pp 24-34. Recuperado de: https://www.redalyc.org/pdf/1812/181229302004.pdf

Manipulador de alimentos (2020). Contaminación de d alimentos. Recuperado de: https://manipulador-dealimentos.com/carnet-curso-contaminacion-de-losalimentos/

Ministerio de Salud de Costa Rica (2005, 15 de noviembre). Reglamento Técnico centroamericano 67.04.50:17Alimentos. criterios microbiológicos para la inocuidad de los alimentos .Recuperado de: https://members.wto.org/crnattachments/2017/SPS/CRI/ 17_2611_00_s.pdf
Ministerio de Salud y protección social (2013, 12 de octubre). Salud pública calidad e inocuidad de alimentos. Recuperado de: https://www.minsalud.gov.co/salud/Documents/generaltempjd/LA\%20INOCUIDAD\%20DE\%20ALIMENTOS\%20 Y\%20SU\% 20IMPORTANCIA\%20EN\%20LA\%20CA DENA\%20AGROALIMENTARIA.pdf

Ministerio de Salud y protección social (Minsalud, 2013) Salud pública calidad e inocuidad de alimentos Recuperado de: https://www.minsalud.gov.co/salud/Documents/generaltemp-

jd/LA \%20INOCUIDAD\%20DE\%20ALIMENTOS\%20 Y\%20SU\%20IMPORTANCIA\%20EN\%20LA\%20CA DENA\%20AGROALIMENTARIA.pdf

Montes, M. (2013). Factores que favorecen el crecimiento de microorganismos. Recuperado de: https://gestionintegra.com/factores-que-favorecen-elcrecimiento-bacteriano/

Mora, J., Calvo, G., ( 2010) Estado actual de contaminación con coliformes fecales de los cuerpos de agua de la Península de Osa. Tecnología en Marcha, 23 (5), pp. 34-40 Recuperado de: file:///C:/Users/ksaravia/Downloads/Dialnet-

EstadoActualDeContaminacionConColiformesFecalesD eL-4835746.pdf

Oficina Comercial de ProChile (2012, 27 de marzo). Estudio de mercado de moluscos congelados para el mercado de Costa Rica. Recuperado de: http://www.siicex.gob.pe/siicex/documentosportal/alert as/documento/doc/284803271rad93039.pdf

Organización de las naciones unidad para la alimentación y la agricultura (2020, 18 de abril). Inocuidad y calidad de los alimentos. Recuperado de: http://www.fao.org/food-safety/background/es/

Organización de las naciones unidas para la agricultura y la alimentación (2010, 22 de abril). Depuración de bivalvos: aspectos fundamentales y prácticos. Recuperado de: http://www.fao.org/3/a-i0201s.pdf

Organización de las naciones unidas para la alimentación y agricultura (2016, 24 de Octubre). Análisis e información comercial en pesquerías. Recuperado de: http://www.fao.org/in-

action/globefish/marketreports/resourcedetail/es/c/522565/

Organización mundial de la salud (2018, 7 de febrero). E. coli. Recuperado de : https://www.who.int/es/newsroom/fact-sheets/detail/e-coli

Organización del sector pesquero y acuícola del istmo 
centroamericano (2014, 9 de junio). manual de buenas prácticas de manejo para el cultivo de moluscos bivalvos. Recuperado de:http://www.isamx.org/sitio/pdfs/Manual\%20de_BPd e_M_Version\%20Digital_011014155613.pdf

Red de Vigilancia para la Conservación y Protección de las Aguas Marinas y Costeras de Colombia (2011, 12 de mayo). Diagnóstico y evaluación de la calidad ambiental marina en el Caribe y Pacífico colombiano red de vigilancia para la conservación y protección de las aguas marinas y costeras de Colombia. Recuperado de: http://www.invemar.org.co/documents/10182/14479/Inf orme REDCAM 2011.pdf
Sello de calidad .(2014).Protocolo particular para acuicultura de mejillones Recuperado de: https://sellocalidadtdf.com.ar/wpcontent/uploads/2014/08/Acuicultura-cultivo-de$\underline{\text { mejillones.pdf }}$

Sosa, D. (2006). Determinación de contaminación por bacterias coliformes fecales en bahía de Jiquilisco, Usulután, utilizando como biomonitor Anadara similis y A. tuberculosa (Tesis doctoral). Universidad de el Salvador Recuperado de: 